\title{
Addressing gaps in quality and safety education during pre-licensure clinical rotations
}

\author{
Susan Pauly-O'Neill, Elizabeth Cooper \\ University of San Francisco School of Nursing and Health Professions, San Francisco, CA, USA \\ Correspondence: Susan Pauly-O'Neill. Address: 2130 Fulton Ave. San Francisco, CA, 94117, USA. Telephone: \\ 01-415-422-6506. Email: paulyoneil@usfca.edu.
}

Received: February 3, 2013

DOI : 10.5430/jnep.v3n11p65
Accepted: March 6, 2012

URL: http://dx.doi.org/10.5430/jnep.v3n11p65

\section{Abstract}

United States national reports have called for improvement in healthcare professions education to better address patient care outcomes. In response, an initiative titled "Quality and Safety Education for Nurses (QSEN)" has been adopted by nursing programs across the nation, which describes the six main competencies to be included in nursing curricula. As early adopters of the QSEN competencies, the University of San Francisco nursing faculty promptly threaded the material throughout the 4-year Bachelor's of Science in Nursing (BSN) curriculum. Confident that the topics were well covered in the classroom, we then sought to learn how often our students practiced these skills during their assigned clinical rotations.

After completing an IRB-approved observational study of junior-level BSN students, we tallied the actual number of minutes spent in each competency area while assigned to the patient care unit. Using a time-on-task author developed QSEN-based tool, we found that our students spent little to no time engaged in quality improvement, evidence based practice, or informatics. This is a very important finding, as it indicates that our students may not be sufficiently developing these particular skills during assigned clinical hours.

Weaving the six QSEN competencies throughout the curriculum is a good start, but as we saw in our observational study, all of the competencies are not equally demonstrated in the clinical setting. Continuing to provide QSEN enriched didactic courses, adding targeted simulation experiences, and nourishing academic/practice partnerships may help bridge the gaps.

\section{Key words}

QSEN use by nursing students, Enhancing clinical education, Prelicensure clinical education

\section{I ntroduction}

A call to transform nursing education in the United States was accepted as a priority in improving patient care in response to the Institute of Medicine (IOM) 2003 report, Health Professions Education: A Bridge to Quality. The report makes recommendations to address the concern that healthcare professionals are not adequately prepared to provide the highest quality and safest medical care possible in our current complex and shifting healthcare arena. To best meet patient needs, the IOM vision for clinical healthcare education is centered on target competencies including patient-centered care, interdisciplinary teams, evidence based practice (EBP), quality improvement (QI), and informatics ${ }^{[1]}$. 
Funded by the Robert Wood Johnson Foundation, a United States national initiative titled "Quality and Safety Education for Nurses (QSEN)" was developed to enhance pre-licensure nursing education to improve outcomes in the healthcare arena. QSEN currently focuses on the IOM recommended competencies with one important addition: safety ${ }^{[2]}$. Sherwood ${ }^{[3]}$, a pioneer in the QSEN initiative, states that the "goal of the competencies is to enable health professionals to deliver patient-centered care, work as part of interdisciplinary teams, practice evidence-based health care, implement quality improvement measures and strategies, and use information technology” (p.14). The challenge became the development of modern nursing curricula that prepare new graduates to contribute to a culture of quality and safety ${ }^{[4-6]}$. As nurses comprise the largest segment of healthcare providers, it remains imperative that undergraduate nursing programs strengthen quality and safety knowledge in their curricula to effectively function as the link to successful adaptation of the healthcare system ${ }^{[7-10]}$.

Today's nurse faculty must create programs that prepare graduates who are able to participate in quality and patient safety initiatives, use skills of inquiry, and employ information technology to gather the evidence they will appraise and integrate to guide practice ${ }^{[9]}$. Presumably, optimal patient care is provided when nurses access the latest research and possess the knowledge, skill, and attitudes (KSAs) needed to exercise judgment based on consensus of expert opinion ${ }^{[11]}$. However, the question still remains whether these competencies are sufficiently honed during pre-licensure nursing education.

The national QSEN initiative provided educators with strategies to transform nursing education. Integration of the six QSEN competencies throughout the curriculum helps to develop a nursing education that would focus on quality and safety in the health care setting. Knowledge, skills and attitude objectives are outlined in each competency. These six QSEN competencies include: patient-centered care, teamwork and collaboration, quality improvement, evidence-based practice, safety, and informatics ${ }^{[3]}$. Table two defines each competency ${ }^{[2]}$.

\section{Background}

As early adopters of the six QSEN competencies, and armed with the lists of the KSAs expected of novice nurses, our School of Nursing and Health Professions faculty promptly threaded the material throughout our four-year pre-licensure nursing curriculum, with an in-depth introduction during a new one-credit hour freshman-level course titled "Introduction to Professional Nursing Practice.” Confident that the QSEN topics were well covered in the classroom during such additional courses as Pharmacology, Nursing Fundamentals, Applied Assessment, Alterations in Health \& Illness, Community/Mental Health Nursing, Evidence-Based Inquiry, Medical Surgical Nursing, Women's Health, Care of Children, and Complex Care Across the Lifespan, we sought to discover how often our students are exposed to the QSEN KSAs during in-hospital clinical rotations. Before embarking on a direct observation in our clinical sites, we looked to the literature for evidence of best practices.

First, the American Association of Colleges of Nursing (AACN) Baccalaureate Essentials ${ }^{[9]}$ call for education in safety, quality improvement, information technology systems, and the appraisal and integration of evidence including the research process itself. In addition, baccalaureate graduates are expected to have competence in the use of information technology (IT) used to gather evidence and guide practice. Hence, formal research courses are offered to comply with these curricular guidelines.

Next, we found numerous exemplars of how to best integrate EBP, QI, and Informatics into pre-licensure didactic courses. For example, Heye and Stevens ${ }^{[12]}$ describe successful implementation of an evidence-based practice project based on priority clinical topics listed in the IOM report. Geller, Bakken, Currie, Schnall, and Larson ${ }^{[13]}$ describe the integration of a web-based reporting system into a course so that some 500 nursing students could report infection control hazards and near misses over a three-year period, offering a hands-on opportunity to employ quality improvement data collection, informatics, and evidence-based practice.

However, the academic approach alone may not provide enough of a foundation for students to develop their own evolving foundation of evidence-based practice ${ }^{[14]}$. In a survey of both Bachelor of Science in Nursing (BSN) and Associates 
Degree in Nursing (ADN) students at 15 QSEN pilot schools, students felt least prepared for evidence-based practice and quality improvement ${ }^{[15]}$. The researchers suggest that particular attention needs to be paid to the demonstration of these competencies in clinical practice. However, limited access to informatics and technology in clinical agencies can be problematic. When IT access is denied such as access to electronic medication administration records, there is risk for reduced care quality and even medication error ${ }^{[16]}$. Fetter ${ }^{[17]}$ reports on surveys of faculty, students and agencies regarding nursing student outcomes and IT, and states that in some cases, student and faculty had no access to healthcare informatics technology. Difficulty in offering access to students and faculty was attributed to privacy and security concerns, resource management, and training demands ${ }^{[17]}$.

Practical application of theoretical knowledge can assist students in understanding how QI affects patient care ${ }^{\text {[18] }}$. To allow students to synthesize classroom learning, Odell ${ }^{[18]}$ introduced a QSEN project assignment in a BSN critical care clinical course. In cooperation with nurse managers, students conducted literature reviews, evaluated the evidence, collected data within the agency, compared the findings to national benchmarks, and presented plans for improvement to the agency.

In a study of student participation in QSEN activities on a Dedicated Education Unit (DEU), 12 BSN students completed activity logs during each clinical shift ${ }^{[19]}$. A DEU is a learning model where the students are placed on a clinical unit that provides their staff members as the expert clinical teachers. In this study, the competencies were well documented with the following examples. Teamwork: Students consulted with a variety of healthcare professionals. EBI and Informatics: Students accessed PDAs for drug data and the hospital intranet for patient education materials. Patient centered care: Students provided comfort measures. Quality improvement: Students became familiar with patient protocols for infection control and seizure precautions. Safety: students complied with medication administration adherence policies and procedures.

Day and Smith ${ }^{[20]}$ describe several strategies that can be used by nurse faculty in the acute care setting where the QSEN quality and safety competencies come alive. They describe "data mining”, in which students collect unit-level data and link their findings to benchmarks (p. 138). In so doing, students are exposed to informatics, quality improvement, and evidence-based practice. Another interesting suggestion posed by the authors is to have students evaluate staff "workarounds" by reviewing institutional policy and subsequently observing several different nurses engaged in the procedure. Work-arounds are described as activities nurses create that deviate from written policies but often work to save time or help adapt to work issues. For the students, when handled appropriately, this exercise is not criticism, but perhaps an opportunity to practice aspects of virtually all QSEN competencies.

Killeen and Barnfather ${ }^{[21]}$ describe a refined clinical network with service-education partnerships where students, faculty, along with the nurse managers collaborate to identify clinical problems. Faculty assists students to collect and synthesize the evidence, and to develop measureable outcomes. Students then present the change project to the hospital staff.

\section{Methods}

In order to gain a snapshot of our own students' QSEN-based experiences in the hospital setting, we targeted a pediatric clinical rotation for direct observation. After obtaining both university and hospital Institutional Review Board for the Protection of Human Subjects (IRBHS)-approval, we conducted a small observational study of junior-level BSN students, to reveal actual "time-on-task" in a variety of QSEN-based activities ${ }^{[22]}$. Time on task refers to the actual time each student spent on specific tasks during their clinical or simulation experience. Fifteen students consented to the study, agreeing to be observed in 3.5 hour blocks.

In order to gain just a quick picture of the actual opportunities available, we observed 13 of these students, one at a time, during their pediatric clinical rotation at two large children's hospitals. An author-developed checklist based on the QSEN 
competencies was used after it had been reviewed and approved by five outside pediatric nursing experts. Three faculty conferred on the use of the tool and discussed how best to ensure inter-rater reliability. Twenty-five observable behaviors that best illustrate QSEN-based nursing actions were listed under subheadings for each QSEN competency (for example: Safety: assesses emergency equipment; Evidence-based practice: locates and reviews policies; Informatics: navigates electronic medical record, etc.). Using a second-hand equipped wristwatch, each of the observers accompanied the students to the hospital unit and tallied the number of minutes the student was engaged in each activity. The total number of minutes in each category was computed and reported as an average ${ }^{[22]}$.

\section{Results}

Our 13 observed students spent most of their time engaged in patient-centered care (98.12 minutes), safety (36.38 minutes), and teamwork and collaboration (28.23 minutes). There was also significant "unengaged time" (25.04 minutes). We were surprised at the results in three of the competency areas. Students spent very few minutes during the observed 210-minute clinical blocks engaged in activities aimed at quality improvement (2.31 minutes), evidence-based practice (5.92 minutes), and informatics (2.96 minutes) (see Table 1). This is a very important finding, as it indicates that our thinking that students are sufficiently developing these particular skills during assigned clinical hours may not be true ${ }^{[22]}$.

What we quickly realized was that learning quality improvement, informatics, and evidence-based practice has been largely left to the classroom. The students are seeing it as theoretical and the real world application may be less obvious. Our dilemma became, "How do we as faculty translate these KSAs into practice during clinical rotations"? And, "How do we nurture and develop them within the context of the clinical setting rather than a textbook”?

Table 1. Mean amount of time spent in each competency area during direct observation

\begin{tabular}{lll}
\hline QSEN COMPETENCY & Mean \# of Minutes & Standard Deviation \\
\hline Patient-centered care & 98.12 & 36.03 \\
Safety & 36.38 & 24.4 \\
Teamwork \& Collaboration & 28.23 & 19.38 \\
(Unengaged time) & 25.04 & 35.86 \\
Evidence-based practice & 5.92 & 9.89 \\
Informatics & 2.96 & 5.79 \\
Quality Improvement & 2.31 & 4.84 \\
\hline
\end{tabular}

\section{Discussion}

Just as nurses are challenged to identify gaps between current and best practice, nurse faculty are challenged to fill gaps in nursing education. For example, students may well be educated about quality improvement, but their preparedness to implement initiatives is limited ${ }^{[18]}$. Students may compile literature reviews for classroom assignments, but the use of information technology to support practice in the clinical area must be integrated into nursing program curricula to fully prepare graduates for the real world of nursing practice ${ }^{[23]}$. AACN supports the idea that clinical experiences provide students with the knowledge and skill to use patient care technologies, electronic health records, and information management systems to deliver safe and effective care ${ }^{[9]}$.

Pre-licensure students, often task-oriented, are busy considering the pathology of the patient condition and devising a plan of nursing care for an individual patient. This leaves little room to practice skills needed in a broader context ${ }^{\text {[20] }}$. Our observational data pointed in this same direction. Additionally, perhaps "unengaged time" could be used by faculty to 
draw attention to the responsibility for creating a safer healthcare system, through the use of activities that highlight the QSEN quality and safety driven competencies.

As we work to fully integrate QSEN into our curriculum, we have come to realize that this is an ongoing process. Recently, we instituted a curricular change by which we added 2 units of didactic course work in informatics to our Evidence Based Inquiry course. This is a purposeful shift to ensure that informatics moves to the forefront and engages students to achieve this competency, as it seems to be difficult to master this competency as a student in the healthcare setting.

The students we observed completed a traditional pediatric clinical assignment of one stable patient per shift, leaving a significant amount of unengaged time. Direct observation revealed that they busy themselves with activities over which they have control, such as talking to patients and their families and to each other. In contrast, the simulation lab in which students complete $25 \%$ of their clinical hours provides a more controlled environment in which students can develop skills not available or appropriate in the traditional clinical setting. Therefore, adding QSEN competencies to every simulation experience is one potential avenue to ensure exposure to the wide array of experiences needed to confer competency. Unlike the hospital setting, these created scenarios in simulation can virtually guarantee exposure to multiple KSAs and QSEN competencies otherwise not available to students ${ }^{[24]}$.

Table 2. QSEN Competencies ${ }^{[25]}$

\begin{tabular}{ll}
\hline QSEN Competency & Description \\
\hline Patient-centered care & $\begin{array}{l}\text { Describes a partnership between the patients, family and health care members. The source of } \\
\text { control in coordinating all care is based on the patient's preferences and needs. }\end{array}$ \\
Teamwork and collaboration & $\begin{array}{l}\text { All members of the healthcare team working together to provide quality patient care. } \\
\text { Evidence-based practice }\end{array}$ \\
Quality improvement & Providing care that is based on the best evidence. \\
Safety & Minimizing the risk of harm to our patients and providers. \\
Informatics & Using technology and information to provide safe patient care. \\
\hline
\end{tabular}

As an outgrowth of our observations, we added QSEN-focused assignments to the pediatric clinical course to be used when appropriate during the shift. Such activities as 1) assess two patient rooms using an environmental safety checklist (Safety);2) choose a nursing policy or procedure in use on the unit and compare it to national standards (Evidence-based Practice); 3) complete near-miss error reports during clinical shift (Quality Improvement); 4) search for credible websites that address patient learning needs (Informatics), etc.

In order for our students to practice safely, they need to have the ability to collaborate with other members of the health care team. Enhanced interprofessional collaboration increases quality at the bedside ${ }^{[26]}$. As nurse educators, we seek to provide settings that foster high-level learning that transfers into complex settings. In order to meet this goal, academia must have strong established relationships with service institutions and work in partnership with the practice areas ${ }^{\text {[27] }}$. Working together as an interprofessional group, with strong support from the top of the organization, will foster stronger academic partnerships ${ }^{[28]}$. With sturdy partnerships, perhaps access to critical experiences in the gap areas may be further explored.

Weaving the six QSEN competencies throughout the curriculum is a good start, but as we saw in our small observational study, all of the competencies may not be equally demonstrated in the clinical setting. Continuing to provide QSEN enriched didactic courses, adding targeted simulation experiences, and nourishing academic/practice partnerships will help bridge the gaps. 


\section{References}

[1] Institute of Medicine. 2003. Health Professions Education: a Bridge to quality. Washington, DC: National Academies Press.

[2] Cronenwett, L., Sherwood, G., Barnsteiner, J., Disch, J., Johnson, J., Mitchell, P., et al. Quality and safety education for nurses. Nursing Outlook. 2007; 55(3): 122-131. PMid:17524799 http://dx.doi.org/10.1016/j.outlook.2007.02.006

[3] Sherwood, G. 2012. Driving forces for quality and safety: Changing mindsets to improve health care. In G. Sherwood \& J. Barnsteiner (Eds.), Quality and Safety in Nursing. West Sussex, UK: Wiley-Blackwell. 2012: 3-21

[4] Sherwood, G. \& Drenkard, K. Quality and safety curricula in nursing education: Matching practice realities. Nursing Outlook. 2007; 55: 151-155. PMid:17524803 http://dx.doi.org/10.1016/j.outlook.2007.02.004

[5] Weinschreider, J. \& Dadiz, R. Back to basics: creating a simulation program for patient safety. Journal of Healthcare Quality. 2009; 31(5): 29-36. http://dx.doi.org/10.1111/j.1945-1474.2009.00044.x

[6] Mansour, M. Current assessment of patient safety education. British Journal of Nursing. 2012; 21(9): 536-543. PMid:22585267

[7] Debourgh, G., \& Prion, S. Patient safety manifesto: A professional imperative for prelicensure nursing education. Journal of Professional Nursing. 2012; 28(2): 110-118. PMid:22459141 http://dx.doi.org/10.1016/j.profnurs.2011.05.001

[8] Thornlow, D. \& McGuinn, K. A necessary sea change for nurse faculty development: spotlight on quality and safety. Journal of Professional Nursing. 2010; 26(2): 71-81. PMid:20304374 http://dx.doi.org/10.1016/j.profnurs.2009.10.009

[9] American Association of Colleges of Nursing. The essentials of baccalaureate education for professional nursing practice. Washington, DC. 2008.

[10] Sherwood, G. Integrating quality and safety science in nursing education and practice. Journal of Research in Nursing. 2011; 16(3): 22640. http://dx.doi.org/10.1177/1744987111400960

[11] Sigma Theta Tau: The Honor Society of Nursing. Evidence-based practice position statement. 2009. Available from: www.nursingsociety.org.

[12] Heye, M., \& Stevens, K. Using new resources to teach evidence-based practice. Journal of Nursing Education. 2009; 48(6): 334-339. PMid:19552320 http://dx.doi.org/10.3928/01484834-20090515-06

[13] Geller, N., Bakken, S.,Currie, L., Schnall, R., \& Larson, E. Infection control hazards and near misses reported by nursing students. American Journal of Infection Control. 2010; 38(10): 811-6. PMid:20621394 http://dx.doi.org/10.1016/j.ajic.2010.06.001

[14] Klassen, P., Karshmer, J., \& Lile, J. Research-based practice: applying the standards in nursing education. Journal of Nursing Education. 2002; 41(3): 121-124. PMid:11939230

[15] Sullivan, D., Hirst, D., \& Cronenwett, L. Assessing quality and safety competencies of graduating prelicensure nursing students. Journal of Healthcare Quality. 2009; 31(5): 29-36.

[16] Institute for Safe Medication Practice. Error-prone conditions that lead to student nurse-related errors. Medication Safety Alert. 2007; 12(21): 1-3. Available from: http://www.ismp.org/Newsletters/acutecare/articles/20071018.asp

[17] Fetter , M. Curriculum strategies to improve baccalaureate nursing information technology outcomes. Journal of Nursing Education. 2009; 48(2): 78-85. PMid:19260399 http://dx.doi.org/10.3928/01484834-20090201-06

[18] Odell, E. Teaching quality improvement to the next generation of nurses. Journal of Nursing Administration. 2011; 41 (12): 553-557. PMid:22094621 http://dx.doi.org/10.1097/NNA.0b013e3182378d8a

[19] McKown, T., McKown, L., \& Webb, S. Using quality and safety education for nurses to guide clinical teaching on a new dedicated education unit. Journal of Nursing Education. 2011; 50(12): 706-710. PMid:22007711 http://dx.doi.org/10.3928/01484834-20111017-03

[20] Day, L. \& Smith, E. Integrating quality and safety content into clinical teaching in the acute care setting. Nursing Outlook. 2007; 55: 138-143. PMid:17524801 http://dx.doi.org/10.1016/j.outlook.2007.03.002

[21] Killen, M., \& Barnfather, J. A successful teaching strategy for applying evidence-based practice. Nurse Educator. 2005; 30(3) 127-132. http://dx.doi.org/10.1097/00006223-200505000-00016

[22] Pauly-O’Neill, S., Prion, S., \& Nguyen, H. Comparison of student QSEN experiences during pediatric clinical and simulation rotations. Journal of Nursing Education, In press.2013.

[23] McNeil, B., Elfrink, V., Bickford, C., Pierce, S., Beyea, C., Averill, C., \& Klappenbach, C. Nursing information technology knowledge, skills, and preparation of student nurses, nursing faculty, and clinicians: A U.S. survey. Journal of Nursing Education. 2003; 42(8): 341-349. PMid:12938896

[24] Durham, C., \& Alden, K. Integrating quality and safety competencies in simulation. In G. Sherwood \& J. Barnsteiner (Eds.), Quality and Safety in Nursing. West Sussex, UK: Wiley-Blackwell. 2012: 227-249.

[25] Quality and Safety Education for Nurses. Available from: http://www.qsen.org/ksas_prelicensure.php. 2009.

[26] Moore, S., Dolansky, M., \& Singh, M. Interprofessional approaches to quality and safety education. In G. Sherwood \& J. Barnsteiner (Eds.), Quality and Safety in Nursing. 2012: 251-266. West Sussex, UK:Wiley-Blackwell.

[27] Emanuel, V., Day, K., Diegnan, L., \& Pryce-Miller, M. Developing evidence-based practice among students. Nursing Times. 2011; 107(49/50): 21-23. PMid:22239047

[28] Karshmer, J. Leadership for academic service partnerships: A mandate for the profession. Nurse Leader. 2010; 8(2): 52-55. http://dx.doi.org/10.1016/j.mnl.2010.01.006 